\title{
Analysis of Stress Distribution in the Forging Press
}

\author{
Zdenek Chval $^{\mathrm{a}}$, Karel Raz ${ }^{\mathrm{a}}$, Milan Cechura ${ }^{\mathrm{b}}$ \\ aUniversity of West Bohemia, Faculty of Mechanical Engineering, Regional Technological Institute, \\ Univerzitni 8, 30614 Pilsen, Czech Republic \\ bUniversity of West Bohemia, Univerzitni 8, 30614 Pilsen, Czech Republic
}

\begin{abstract}
Mechanical properties of forging presses are the most important information for their designers. It includes besides other things knowledge of critical points where destruction may occur, because reliability of the press is a basic condition for the reliable forging process.

This paper deals with an analysis of the stress distribution in the frame of forging press, identification of critical points and subsequently represents a durability balance in critical points. The presented results can be used especially to make optimal design of new forging presses.
\end{abstract}

Keywords: mechanical forming machines; forging press; stress distribution; FEM analysis; durability
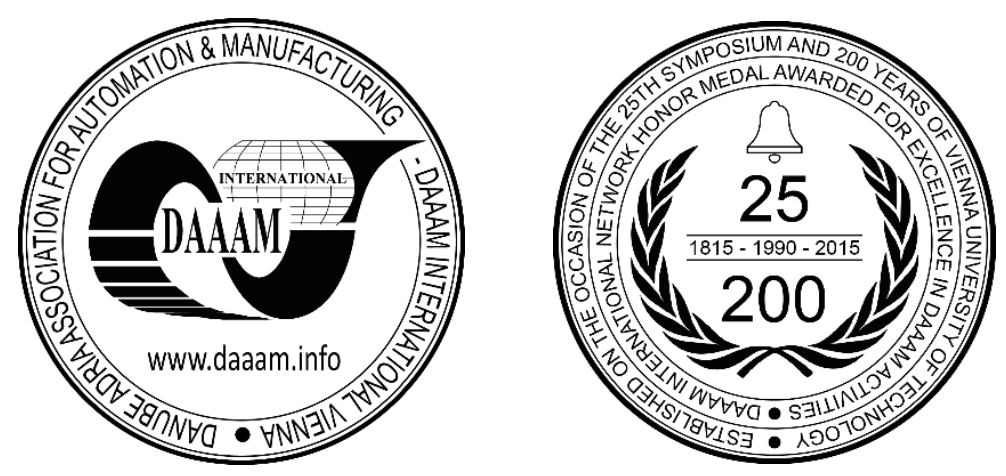

This Publication has to be referred as: Chval, Z[denek]; Raz, K[arel] \& Cechura, M[ilan] (2016). Analysis of Stress Distribution in the Forging Press, Proceedings of the 26th DAAAM International Symposium, pp.0488-0493, B. Katalinic (Ed.), Published by DAAAM International, ISBN 978-3-902734-07-5, ISSN 1726-9679, Vienna, Austria DOI: $10.2507 / 26$ th.daaam.proceedings. 065 


\section{Introduction}

One of the most important machine parameters that need to be considered when buying a new machine is its durability. This is the running time of the machine before the first occurrence of defects, usually cracks on components of machines. It is therefore important to be interested how long and with what load the machine can be operated reliably. In the long term, it is important to know if the most stressed functional parts of the machine will start to crack shortly after the warranty expires, or the machine survives a generation in perfect condition. One of the most commonly used machines in forging companies is a crank mechanical press for die forging. Therefore, this machine is suitable to demonstrate its durability at different sizes of its loading. In this machine is the most frequent destruction on the press frame. Therefore, the durability analysis was made on the forging press frame. $[1,3]$

\section{Diagnosis of the most loaded places of forging press frame}

All calculations were performed using the virtual modelling, using FEM analysis and software Siemens NX 10. Calculations were made for centric and eccentric loading presses, with nominal force $25 \mathrm{MN}$ and with an eccentricity of $300 \mathrm{~mm} .[1,2,3,4,9]$

Fixing of press was made on the bottom of the press frame over a circular area defined by the axis of the frame. All inserted parts of the press (eccentric shafts, pin, connecting rods, and anchors) were inserted through contacts. In anchored forging press the anchor preload was set as 1.4 times of the nominal force. The clearance in the guidance was set at $0.1 \mathrm{~mm}$ and $0.2 \mathrm{~mm}$ in the bearings. [5, 6, 7,8,10].

\subsection{Forging press without anchors}

Figure 1 shows the locations with the highest stress in the press frame without anchors. These points are important because they are potential points of the first destructions.

Table 1 shows the maximum stress value in the monitored points with various loads, 100,75 and $50 \%$. As expected, dependency: loading force $\times$ stress in the press frame is a linear. The percentage variations are caused by inaccurate FEM calculations (influence of mesh, etc.).
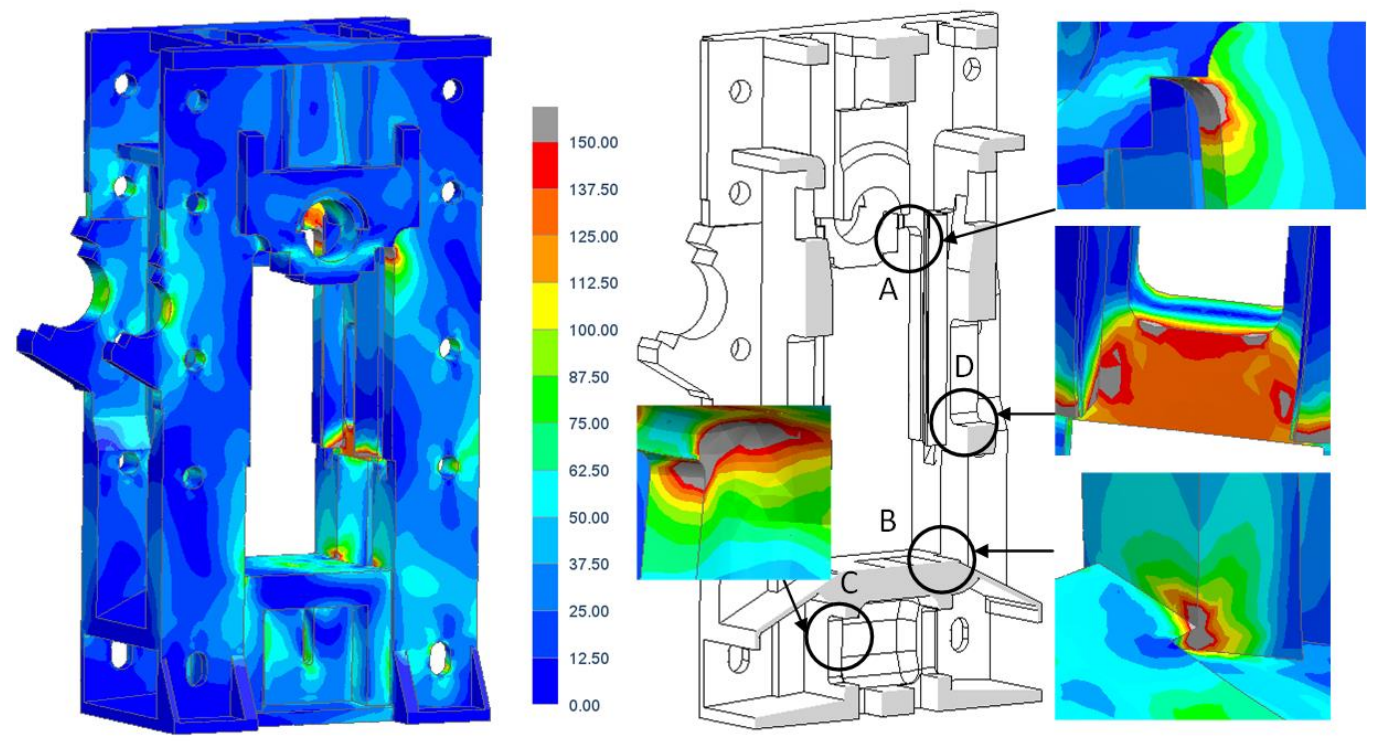

Fig. 1. Forging press 25MN without anchors, Von-Mises stress [MPa]

\begin{tabular}{lcccccccccc}
\hline $\begin{array}{l}\text { Stress } \\
\text { point }\end{array}$ & F 100\% & \multicolumn{3}{c}{$\begin{array}{c}\text { F 75\% } \\
\text { Eccentric load }\end{array}$} & F 50\% & F 100\% & \multicolumn{1}{c}{$\begin{array}{c}\text { F 75\% } \\
\text { Centric load }\end{array}$} & F 50\% \\
\hline A & $\mathbf{3 1 8}$ & 241 & $76 \%$ & 161 & $51 \%$ & $\mathbf{1 5 3}$ & 116 & $76 \%$ & 77 & $50 \%$ \\
B & $\mathbf{2 0 6}$ & 153 & $73 \%$ & 102 & $50 \%$ & $\mathbf{1 6 6}$ & 124 & $75 \%$ & 82 & $49 \%$ \\
C & $\mathbf{2 2 1}$ & 166 & $75 \%$ & 110 & $50 \%$ & $\mathbf{1 4 5}$ & 106 & $73 \%$ & 72 & $50 \%$ \\
D* & $\mathbf{2 1 0}$ & 160 & $76 \%$ & 105 & $50 \%$ & & & & & \\
\hline
\end{tabular}

*Point $\mathrm{D}$ is not stressed in centric case, because ram is not touched to ram guidance

Table 1. Values of the maximum stress of the press frame without anchors, eccentric and centric load and varying loading force $(\mathrm{MPa})$ 


\subsection{Forging press with anchors}

Figure 2 shows the locations with the highest stress in the press frame with anchors. Anchors in this case are inserted only using a contact without entering preload. Anchors are used in this case only as an additional component in the same mode of load as press frame.

Table 2 shows the maximum stress value in the monitored points with various loads, 100, 75 and $50 \%$. As expected, dependency: loading force $\times$ stress in the press frame is a linear again.
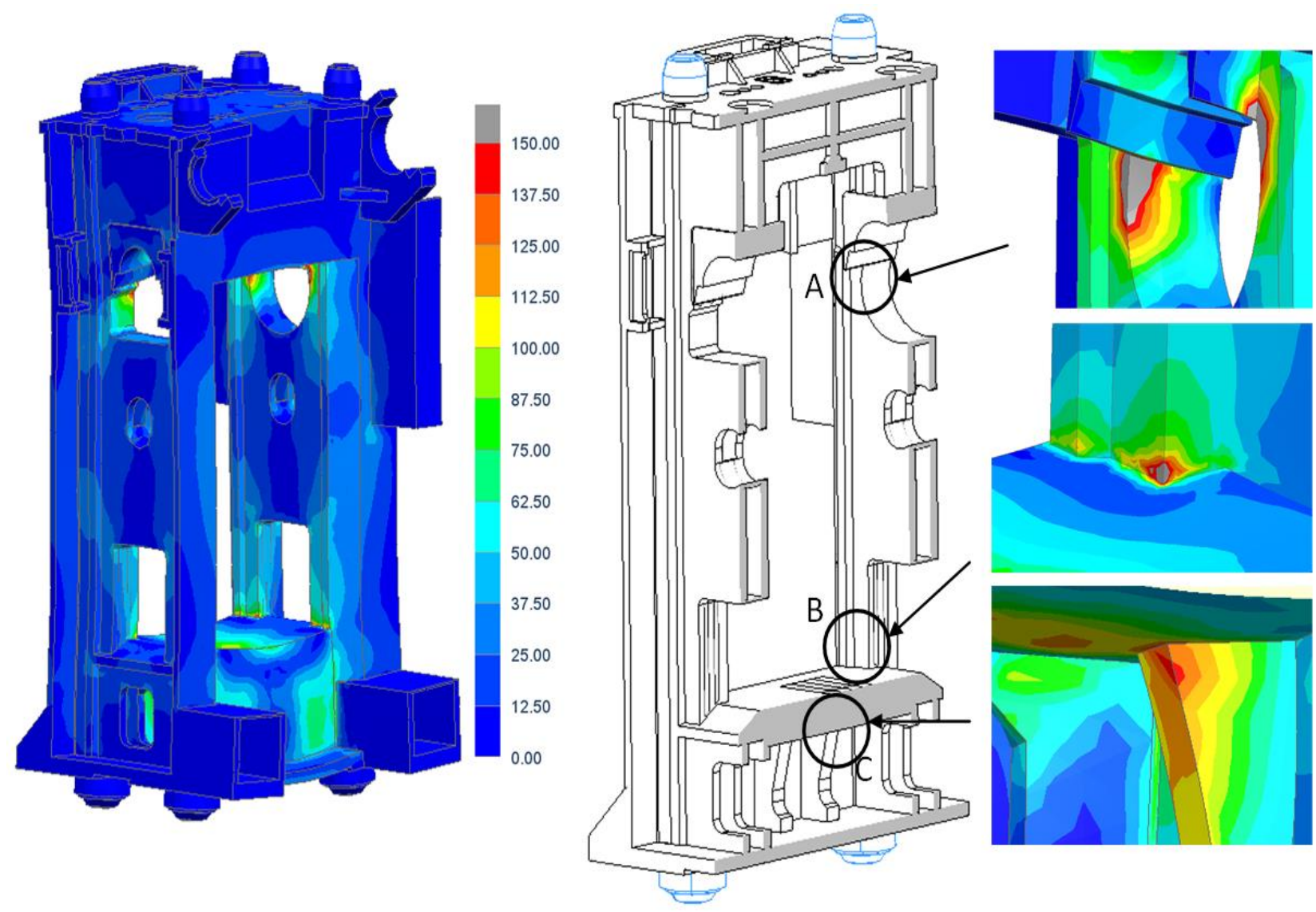

Fig. 2. Forging press $25 \mathrm{MN}$ with anchors, Von-Mises stress [MPa]

\begin{tabular}{lcccccccccc}
\hline $\begin{array}{l}\text { Stress } \\
\text { point }\end{array}$ & F 100\% & \multicolumn{3}{c}{$\begin{array}{c}\text { F 75\% } \\
\text { Eccentric load }\end{array}$} & F 50\% & F 100\% & \multicolumn{2}{c}{$\begin{array}{c}\text { F 75\% } \\
\text { Centric load }\end{array}$} & F 50\% \\
\hline A & $\mathbf{2 2 2}$ & 177 & $80 \%$ & 115 & $52 \%$ & $\mathbf{1 7 5}$ & 130 & $74 \%$ & 89 & $51 \%$ \\
B & $\mathbf{2 2 5}$ & 164 & $73 \%$ & 105 & $47 \%$ & $\mathbf{1 8 8}$ & 141 & $75 \%$ & 91 & $48 \%$ \\
C & $\mathbf{1 4 5}$ & 108 & $74 \%$ & 73 & $50 \%$ & $\mathbf{1 6 0}$ & 120 & $75 \%$ & 79 & $49 \%$ \\
\hline
\end{tabular}

Table 2. Values of the maximum stress of the press frame with anchors, eccentric and centric load and varying loading force $(\mathrm{MPa})$

Stress increasing by centric load is caused by rib placing. Both frames ( 1 and 2$)$ reach a relatively high stress in the monitored points, especially when forging is eccentric. In the following case, preloaded anchors reduce the high stress in the monitoring points.

\subsection{Forging press with preloaded anchors}

Figure 3 shows the locations with the highest stress in the press frame with preloaded anchors. Table 3 shows the maximum stress value in the monitored points with various loads, 100, 75 and 50\%. The dependency: loading force $\times$ stress in the press frame is not linear. Nonlinear dependence is caused by preloaded anchors. 

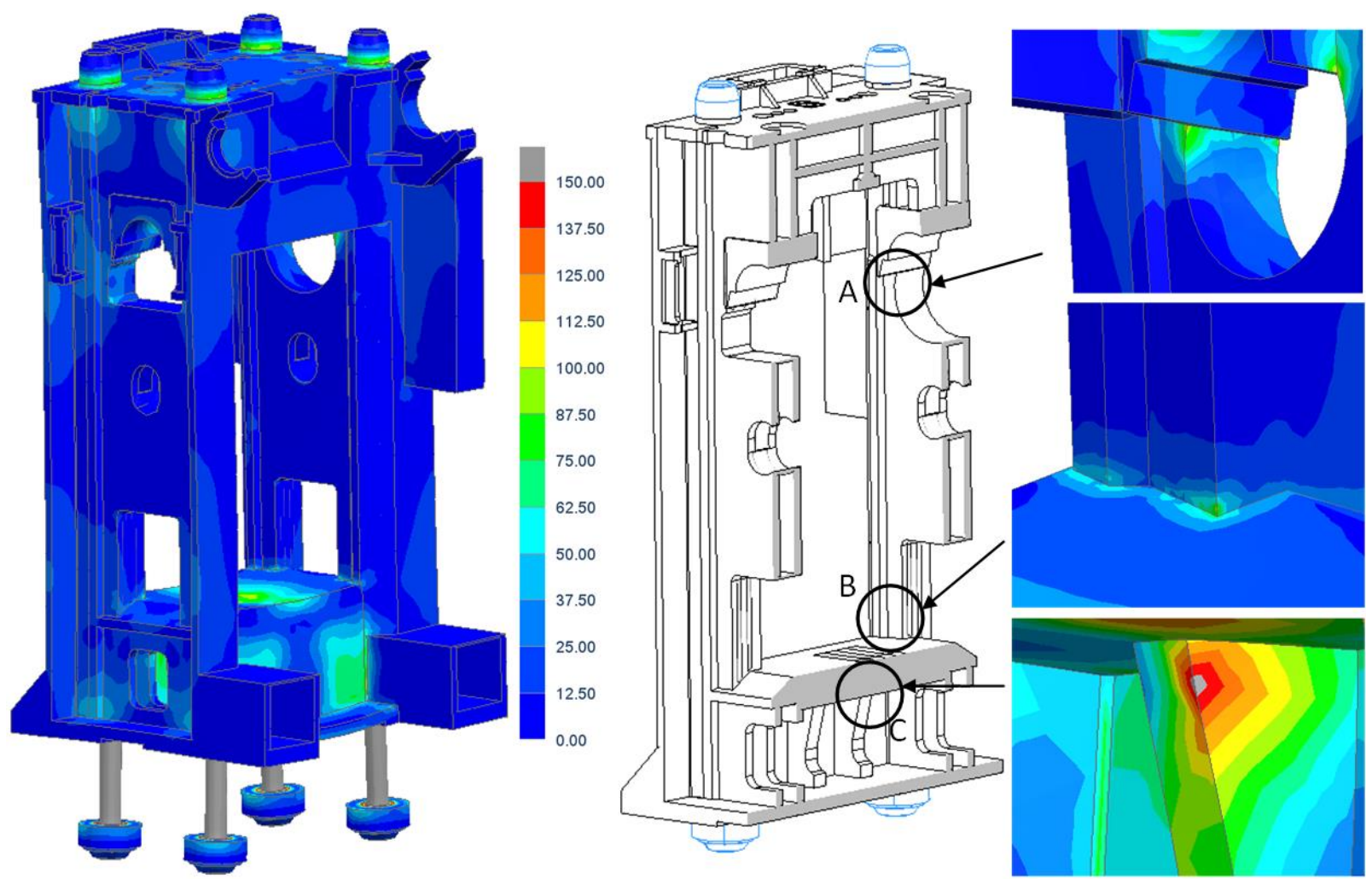

Fig. 3. Forging press $25 \mathrm{MN}$ with preloaded anchors, Von-Mises stress [MPa]

\begin{tabular}{|c|c|c|c|c|c|c|c|c|c|c|}
\hline \multirow{3}{*}{$\begin{array}{l}\text { Stress } \\
\text { point } \\
\text { A }\end{array}$} & \multirow{3}{*}{$\begin{array}{c}\text { F 100\% } \\
215\end{array}$} & \multirow{2}{*}{\multicolumn{2}{|c|}{$\begin{array}{c}\text { F 75\% } \\
\text { Eccentric load }\end{array}$}} & \multicolumn{2}{|c|}{ F 50\% } & \multirow{3}{*}{$\begin{array}{c}\text { F 100\% } \\
\\
97\end{array}$} & \multirow{2}{*}{\multicolumn{2}{|c|}{$\begin{array}{l}\text { F 75\% } \\
\text { Centric load }\end{array}$}} & \multicolumn{2}{|c|}{ F 50\% } \\
\hline & & & & & & & & & & \\
\hline & & 136 & $63 \%$ & 57 & $27 \%$ & & 54 & $56 \%$ & 25 & $26 \%$ \\
\hline B & 240 & 125 & $52 \%$ & 48 & $20 \%$ & 146 & 91 & $62 \%$ & 32 & $22 \%$ \\
\hline $\mathrm{C}$ & 190 & 105 & $55 \%$ & 69 & $36 \%$ & 122 & 90 & $74 \%$ & 22 & $18 \%$ \\
\hline
\end{tabular}

Table 3. Values of the maximum stress of the press frame with preloaded anchors, eccentric and centric load and varying loading force $(\mathrm{MPa})$

\begin{tabular}{lccc}
\hline Point/ press & 1 & 2 & 3 \\
\hline A & 48 & 76 & 43 \\
B & 81 & 85 & 67 \\
C & 65 & 109 & 60 \\
\hline
\end{tabular}

Table 4. Average \% ratio, eccentric/centric load

For other durability balance was removed point $\mathrm{C}$. This point is below the work desk on the rib. Stress at this point is due mainly to pressure, which usually does not lead to cracking.

\section{Durability balance}

Subsequently, virtual evaluation of durability was made in the monitored points for whole variants - centric and eccentric load 100, 75 and 50\%. 


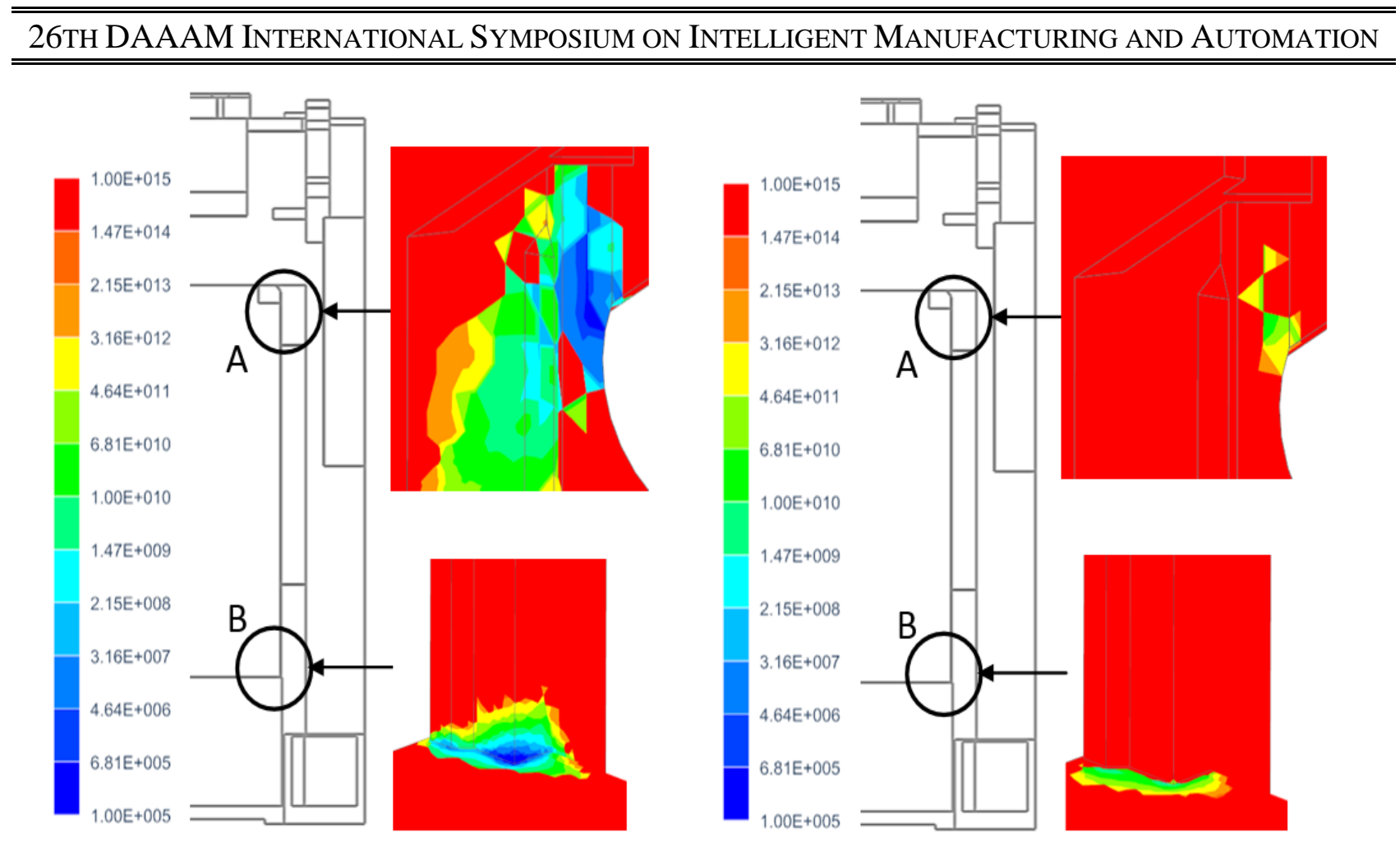

Fig. 4. Display of durability, example of eccentric load, 100\% and 50\%

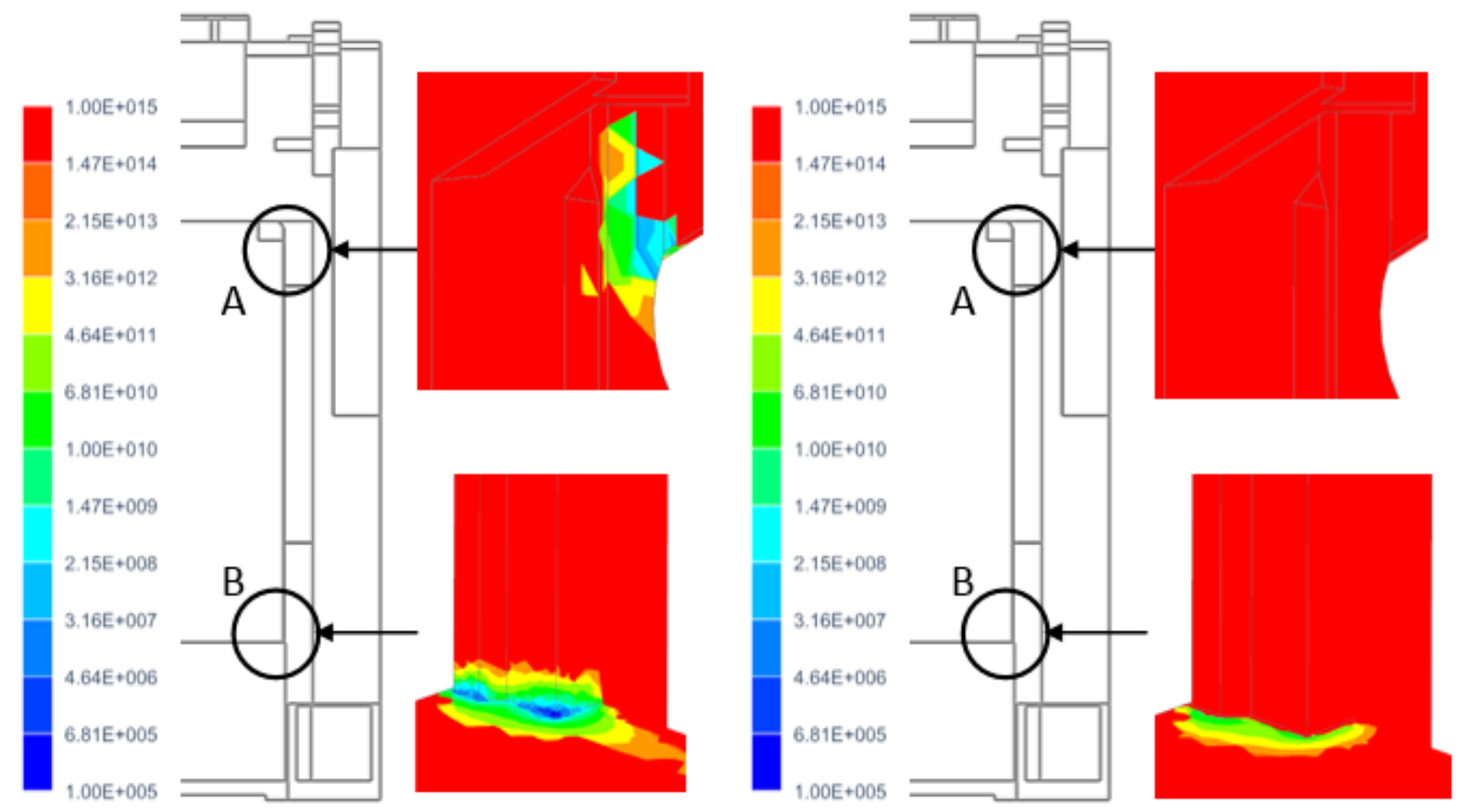

Fig. 5. Display of durability, example of centric load, 100\% and 50\% 


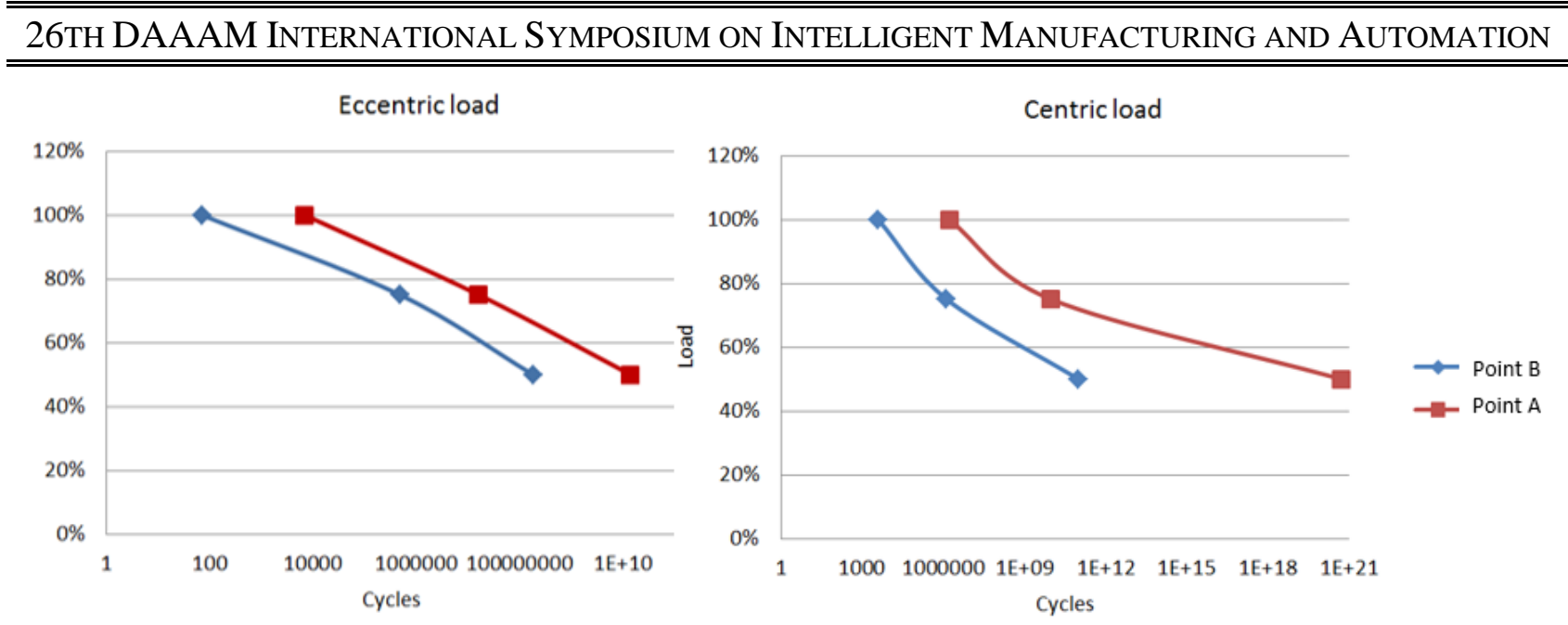

Fig. 6. Display of durability depending on the load on the press with prestressed anchors loaded by eccentric and centric force

\section{Conclusion}

From results of stress and durability is obvious that stress (durability) of the monitored points on press with preloaded anchors increases nonlinearly with strength increasing. This is valid for centric and eccentric loading.

These dependencies show that for example when a load is $75 \%$, it is possible to achieve 1000 times greater number of load cycles comparing to $100 \%$ load. It is obvious that any overloading rapidly decreases the durability of the press.

These analysis conclusions should be warning for the crank presses operator, as it clearly shows how the operator can dramatically shorten or lengthen the lifetime of the press. These presented results leads to optimal design of new forging presses. Further research should focus on optimum stress distribution in the press frame during eccentric loading. One possibility is different dimensions of the frame depending on the location of the force as well as various set of preloaded anchors.

\section{Acknowledgements}

This paper is based upon work sponsored by project TA ČR, project TE01020075.

\section{References}

[1] M. Cechura, Z.Chval, Monitoring Extremly Stressed Points on Stands of Forging Presses, 25th DAAAM International Symposium on Intelligent Manufacturing and Automation 2014, Procedia Engineering 100 (2015), p. $841-846$.

[2] A. García-Domínguez, J. Claver, A.M. Camacho, , M.A. Sebastián, Comparative Analysis of Extrusion Processes by Finite Element Analysis, 25th DAAAM International Symposium on Intelligent Manufacturing and Automation 2014, Procedia Engineering 100 (2015), p. 74 - 843.

[3] M. Zahalka, Modal Analysis of Hydraulic Press Frames for Open Die Forging, 24th DAAAM International Symposium on Intelligent Manufacturing and Automation 2013, Procedia Engineering 69 (2014), p. 1070 - 1075.

[4] M. Cechura, Z. Chval, Kovarenstvi. Convectional versus multiple operating press, May 2013/17, 67-70, ISSN 12139289, Brno, 2013, p. 846

[5] M. Zahalka, J. Staněk, Options of Advanced Simulations of Crank Presses Loading, 25th DAAAM International Symposium on Intelligent Manufacturing and Automation 2014, Procedia Engineering 100 (2015), p. 891 - 898.

[6] M. Cechura, J. Housa, Energy analysis of forming machines and further proposals for decreasing of energy consumption, research report, V- 11-037, VSCVTT, Prague, 2011.

[7] M. Cechura, J. Smolik, Development of New and innovations of existing construction solutions of forming machines, research report, CKSVT-WP11, CVTS, Pilsen, 2012.

[8] J. Hlavac, M. Cechura, V. Kubec, Technologia, The development of virtual simulation in design of mechanical presses, September 2011/13, ISBN 978-80-227-3545-2, Bratislava, 2011, p. 61.

[9] A.P.Karamyshev, The production of a machine designed for the cold radial cyclic forging of solid and tube billets, WIT Transactions on Ecology and the Environment, ISSN: 17433541, April 2014, p. 169-177, 25

[10] Z. Chval, Effect of heat load to the forming machines, MM Science Journal, ISSN: 1803-1269, October 2013, p. 418-421 